\title{
HACIA UNA NUEVA VICEPRESIDENCIA. REFLEXIONES DESDE EL CASO NORTEAMERICANO
}

MARIO D. SERRAFERO 
SUMARIO

I. INTRODUCCIÓN. II. LOS PROBLEMAS DE LA VICEPRESIDENCIA: LA TEORÍA Y LOS HECHOS. III. LA VICEPRESIDENCIA EN LOS ESTADOS UNIDOS. IV. PRECEDENTES Y PRÁCTICAS PARACONSTITUCIONALES. V. INHABILIDAD Y VACANCIA PRESIDENCIAL. VI. LA EXPERIENCIA DEL CASO NORTEAMERICANO. VII. CONCLUSIONES. ¿UNA NUEVA VICEPRESIDENCIA? 


\title{
HACIA UNA NUEVA VICEPRESIDENCIA. REFLEXIONES DESDE EL CASO NORTEAMERICANO
}

\author{
MARIO D. SERRAFERO*
}

\section{INTRODUCCIÓN}

La vicepresidencia es una institución receptada por casi todos los países latinoamericanos. Alrededor de ella existen no pocos misterios y paradojas, como así también un incipiente debate, en algunos países, sobre su verdadera utilidad. Lo cierto es que han sido significativos los problemas que rodearon a la vicepresidencia latinoamericana en la tercera ola de la democratización, y aún antes. En Argentina, Bolivia, Colombia, Ecuador, Paraguay, para mencionar algunos casos, encontramos conflictos significativos cuando no de extrema gravedad en la relación entre el presidente y el vicepresidente.

Según se ha sostenido en estudios anteriores ${ }^{1}$, gran parte del problema reside en el diseño original de la institución. Para el presidente, el vice es una suerte de sombra que le pisa los talones y que apuesta, consciente o inconscientemente, a su desgracia. Para el vicepresidente su lugar es el de la máxima paradoja: de no ser nada puede convertirse en todo, si esa desgracia finalmente le ocurre al mandatario. Por cierto esto no es siempre ni necesariamente así, pero el diseño ins-

* Doctor en Derecho Público por la Universidad de Buenos Aires y Doctor en Ciencias Políticas y Sociología por la Universidad Complutense y el Instituto Universitario Ortega y Gasset, Madrid. Es investigador Principal del Consejo de Investigaciones Científicas y Tecnológicas (CONICET) de la Argentina y Miembro de Número de la Academia Nacional de Ciencias Morales y Políticas de la Argentina.

1 Ver Serrafero, Mario D. (1999), El poder y su sombra. Los vicepresidentes, Buenos Aires, Editorial de Belgrano. 
titucional del presidencialismo en general y de la vicepresidencia en particular puede coadyuvar a que estas fantasías tengan intento de concreción. El vicepresidente mientras está el presidente gobernando prácticamente no ocupa ningún papel relevante. En algunos países, como en la Argentina, tiene a su cargo la presidencia del Senado, pero aún así aparece desdibujado de la escena política y gubernamental.

En América Latina no se ha producido una evolución de la institución como ocurrió en los Estados Unidos. El análisis del caso norteamericano puede ser un buen ejemplo a tener en cuenta pues sin reformas constitucionales, una serie de prácticas paraconstitucionales ha modificado el perfil y la importancia de la vicepresidencia. Casi desde los comienzos de la vida institucional del país del norte la vicepresidencia fue un lugar institucional devaluado, existieron conflictos entre presidentes y vices y hasta se pensó en eliminar la figura.

La vicepresidencia ha merecido un espacio significativo en la investigación jurídica y politológica norteamericana, en comparación con la escasez que se observa en los estudios y latinoamericanos ${ }^{2}$. El interés sobre la institución ha sido - y es - variado. La pregunta esencial es para qué sirve realmente la vicepresidencia y cuál ha sido su desempeño histórico. Algunos trabajos han enfocado temas tales como el perfil y los rendimientos del vicepresidente, su nominación, capacitación, relaciones con el presidente, influencia en las campañas y resultados electorales, etcétera. No obstante este corpus investigativo, los propios autores norteamericanos expresan que es poco lo que se sabe, a pesar de haberse avanzado bastante en los últimos tiempos. No hay que olvidar que la vicepresidencia en los EE.UU., desde hace varias décadas, ha ganado un considerable espacio en el sistema institucional. Ha crecido, ha consolidado más funciones y tiene una visibilidad mayor a la que tradicionalmente tenía, aunque persiste aún la imagen devaluada de su figura.

El estudio comienza con una referencia teórica y empírica sobre la vicepresidencia en América Latina y de algunos de los problemas evidenciados a partir

\footnotetext{
2 Entre otros trabajos, pueden consultarse: Goldstein, Joel K. (1982): The Modern American Vice Presidency, Princeton University Press; Light, Paul C. (1984), Vice Presidential Power, The Johns Hopkins University Press; Goldstein, Joel (2008): «The Rising Power of the Modern Vice Presidency», en Presidential Studies Quarterly. También resultan de interés: Learned, H. B. (1912), «Some Aspects of the Vice-Presidency», en Proceedings of the American Political Science Association, Vol 9, pp. 162-177; Rossiter, Clinton L. (1948), Political Science Quarterly, Vol. 63, n. ${ }^{\circ} 3$, pp. 383-403; Durham Omer, G. (1948). «The Vice-Presidency», en The Western Political Quarterly, Vol. 1, n. ${ }^{\circ}$ 3, pp. 311-315; David, Paul T. (1967), «The Vice Presidency: Its Institutional Evolution and Contemporary Status», en The Journals of Politics, Vol. 29, n. ${ }^{\circ}$ 4, pp. 721-748; Light, Paul C. (1983-1984)), «Vice-Presidential Influence under Rockefeller and Mondale», en Political Science Quarterly, Vol 98, n. ${ }^{\circ} 4$, pp. 617-640.
} 
de la tercera ola de la democratización. Pasa luego a explorar la evolución de la figura en los Estados Unidos a lo largo de su historia. Finalmente se brinda una reflexión sobre las posibilidades que se abren, en América Latina, sobre esta controversial figura. La decisión sobre qué hacer con la vicepresidencia pasa por distintas alternativas: a) su eliminación; b) la modificación de sus contornos en una eventual reforma constitucional —o a través de legislación del Congreso-, c) el inicio de prácticas paraconstitucionales. Y la cuestión, en caso de mantenerse la institución, es que nuevo perfil debería darsele a la vicepresidencia. Para ello es necesario realizar investigaciones acerca de la vicepresidencia latinoamericana desde un enfoque politológico, que muestre a la institución en perspectiva comparada, su diseño, funciones y rendimientos. Mientras tanto, es conveniente la instalación de un debate acerca de la institución y, en este sentido, las observaciones sobre la experiencia americana pueden ser un buen disparador. Asimismo, los países latinoamericanos suelen realizar reformas políticas, por lo cual resulta también útil tener en cuenta la evolución de la institución en los Estados Unidos, si bien ello no suple la tarea de investigación en cuanto a la necesidad de conocer más y mejor acerca de la vicepresidencia latinoamericana.

En síntesis, la perspectiva asumida en este trabajo es útil tanto para una reforma normativa de la institución, como para la emergencia de nuevas prácticas paraconstitucionales que hagan de esta figura constitucional una pieza a favor de la continuidad y la gobernabilidad política del régimen democrático. El recorrido sobre la evolución de la vicepresidencia norteamericana puede ser un buen punto de partida — entre otros posibles — para un debate postergado que abra la puerta a investigaciones sobre la institución y para reflexionar acerca de la necesidad de una nueva vicepresidencia en América Latina teniendo en cuenta los problemas teóricos y empíricos que rodean a esta figura institucional.

\section{LOS PROBLEMAS DE LA VICEPRESIDENCIA: LA TEORÍA Y LOS HECHOS}

Es realmente curioso que prácticamente no hayan existido investigaciones acerca de la vicepresidencia en América Latina. Sólo se encuentran comentarios o apreciaciones, pero resultan escasos los trabajos teóricos y empíricos centrados en la institución.

Cabe referir a Juan Linz, quien dentro del cuestionamiento general que realizaba al sistema presidencial, trataba la institución de la vicepresidencia en los siguientes términos: «En caso de muerte o renuncia por una u otra razón, el sistema presidencial, presumiblemente asegura una sucesión automática, no 
permitiendo vacíos de poder ni interrupciones. Sin embargo, la sucesión por el vicepresidente, quien completa el mandato, que ha funcionado relativamente sobre ruedas en la historia reciente de los EE.UU., plantea algunas veces serios problemas... el Vicepresidente podría haber sido electo por un partido diferente o coalición. En ese caso, aquellos que apoyaron al anterior presidente pueden sentir que el sucesor no los representa y que no tiene la legitimación popular y democrática requerida para el cargo... Hay indudablemente casos en los cuales el vicepresidente ha sido nominado para equilibrar la fórmula y por lo tanto significa una discontinuidad. Casos en los cuales el presidente ha impuesto un candidato débil para acompañarlo en la fórmular porque de esta manera no representa un desafío potencial en su poder, o cuando ha elegido un vice por su relación personal, como ser su esposa. Nadie puede asegurar en el sistema presidencial que los votantes o la dirigencia política del país hubieran elegido al vicepresidente para ejercer el poder que ellos quisieron darle al presidente pasado. La continuidad con la sucesión automática que el sistema presidencial parece asegurar, puede ser más aparente que real. Existe, obviamente, la posibilidad de un gobierno provisorio hasta las nuevas elecciones que tendrán lugar en fecha lo más temprano posible. Pero no es seguro que la seria crisis que provocó la necesidad de la sucesión pueda ser el mejor momento para soportar una nueva elección presidencial» ${ }^{3}$.

En síntesis, de su posición resultarían las siguientes hipótesis que denotan diferentes situaciones y efectos: 1) casos en que la vicepresidencia se elige para «equilibrar» las fórmulas lo cual no significa necesariamente continuidad; 2) casos en que se impone un candidato débil para que no desafíe el poder del presidente; 3) casos en que se nombra al candidato por su relación personal (por ejemplo, esposa); 4) la continuidad no parece estar asegurada y puede ser más aparente que real; 6) los conflictos entre el presidente y el vice pueden ser muy significativos.

Estas consideraciones las realizaba Linz a mediados de los años ochenta y, en otra versión de su ya famoso trabajo sobre el presidencialismo, agregaba los conflictos frecuentes que podían suscitarse entre el presidente y el vicepresidente $^{4}$. Dice Linz: «Conflicts between presidents and vicepresidents have been frequent. We only have to think of Janio Quadros and Goulart, Frondizi and

3 Linz, Juan (1988): «Democracia Presidencialista o Parlamentaria», en Consejo para la Consolidación de la Democracia, Presidencialismo vs. Parlamentarismo, Bs. As., Eudeba, pág. 38.

4 En Linz, Juan y Valenzuela, Arturo (Ed.) (1994): The Failure of Presidential Democracy, Vol. 2 The case of Latin America, The Johns Hopkins University Press, pág. 33. 
Gómez, Alfonsín and Martínez and most recently Corazón Aguino and Laurel (who went as far as conspiring against President Aquino)».

Más allá de las apreciaciones de Linz, sólo algunos pocos trabajos ${ }^{5}$, desde una perspectiva politológica, introdujeron miradas levemente diferentes a la «visión clásica» proveniente del derecho constitucional y que concebía a la vicepresidencia como una sucesión automática en caso de que el presidente, por las razones que fueran, no pudiera continuar más en su cargo. Es así que la vicepresidencia prácticamente ha pasado inadvertida como objeto de estudio en los análisis politológicos.

En una extensa investigación ${ }^{6}$ acerca de los distintos contornos de su figura y las hipótesis ficticias o erróneas que emergían de la referida "visión clásica», se formularon hipótesis que pretendieron delinear una suerte de teoría acerca de la vicepresidencia.

En el mencionado trabajo — imposible de referir aquí por su extensión- se intentó una clarificación y sistematización de los problemas de un modo diferente al que había sido habitual. Sin excluir el enfoque normativo — propio del derecho constitucional_- , se lo incluyó dentro de una mirada más global utilizando herramientas del análisis politológico. En este sentido, el enfoque le prestó interés especial a la naturaleza de la figura, sus probables efectos y los incentivos de comportamientos que de ella pueden derivarse. Asimismo, se distinguió entre gobierno y régimen para mejor encuadrar los fenómenos relativos al tema de la continuidad y la discontinuidad dentro del campo de la sucesión presidencial. Y, por último, se diferenció entre tres situaciones distintas que hacen al binomio del Ejecutivo y que prácticamente no se habían distinguido con anterioridad: a) como contexto electoral; b) como contexto de gobierno; y c) como contexto de sucesión. Son tres contextos elementales o esenciales a partir de las cuales la vicepresidencia y su conexión con la presidencia adquieren sentido diferente. En cuanto al contexto o fórmula electoral, la vicepresidencia es vista desde los motivos de designación de los candidatos, los modos y los procedimien-

5 Para el caso de la Argentina puede verse Agulla, Juan Carlos (1994): «El Estado Federal y el Senado», en Labourdette, Sergio (Comp.), Política y Constitución. Aportes para un debate necesario, Bs. As., A-Z Editora, pp. 31 y 32 y Nino, Carlos (1991): «El presidencialismo y la justificación, estabilidad y eficiencia de la democracia», en Presidencialismo y Estabilidad Democrática en la Argentina, Bs. As., C.E.I., pág. 25. También merece citarse el trabajo de Sribman, Ariel D. (2010): «La Vicepresidencia Argentina (1983-2009)», en Cadernos de Estudos Latino-Americanos, n. ${ }^{\circ} 10$. Para las sucesiones por crisis presidenciales en América Latina que involucran a vicepresidentes puede verse Hochstetler, Kathryn y Samuels, David (2011): «Crisis and Rapid Reequilibration. The Consequences of Presidential Challenge and Failure in Latin America, Comparative Politics, Vol. 43, n. ${ }^{\circ}$, pp. $127-145$.

6 Serrafero, Mario D. (1999), El poder y su sombra. Los vicepresidentes, citado anteriormente. 
tos de selección, la elección del binomio en los comicios y todos los efectos que pueden derivarse de tales instancias. Excede los requisitos normativos para la elección de la vicepresidencia y se interna en fenómenos netamente políticos.

En relación con el binomio y el contexto de gobierno se trata de los modos de coexistencia entre presidente y vice mientras están ambos en sus funciones, la relaciones que entre ellos pueden tejerse y desarrollarse, y sus distintas consecuencias. Finalmente, el contexto de sucesión se refiere al reemplazo o la supuesta continuidad automática que implicará la figura de la vicepresidencia -según la visión clásica- distinguiéndose distintas situaciones y efectos según se trate de la continuidad de los gobiernos o del régimen.

En relación a los tres contextos, han existido y existen problemas que tornan dificultosa a la vicepresidencia en relación con el presidente en particular y el sistema político en general. En el contexto electoral los problemas suelen ser aparentemente menores, pues se refiere al principio de la relación, aunque la mala designación de un candidato a ese cargo puede generar problemas con posterioridad. Piénsese en alguien que es elegido sólo por el caudal electoral que puede aportar, pero que puede no tener buena sintonía con el presidente lo cual se pondrá en evidencia en el contexto de gobierno en los años en el poder. Incluso existen casos en que los candidatos a presidente y vice se ubicaban en líneas políticas francamente opuestas. También puede ser alguien que no esté a la altura de las circunstancias y llegue a ejercer el poder en ocasión de la vacancia definitiva de la presidencia.

En el contexto de gobierno, cuando coexisten presidente y vice, es cuando suelen generarse problemas y conflictos que pueden tener efectos en la propia gobernabilidad del sistema político. Serían los casos de vicepresidentes conflictivos que pueden ingresar en el terreno francamente opositor. También los casos en que los presidentes confinan a los vices a un lugar de soledad e indiferencia y el conflicto permanecer en estado latente. Situaciones de extrema desconfianza del presidente en su vice y de actitudes del vice que lo ubican en la vereda opuesta al presidente tornándose la situación cada vez más conflictiva. Incluso la oposición puede ver al presidente como una pieza de conspiración contra el mandatario. En relación al contexto de sucesión, la experiencia empírica no parece darle la razón a la «visión clásica» que augura una suerte de continuidad automática del vice. Por el contrario, la asunción definitiva del vicepresidente como presidente suele implicar un nuevo gobierno y para su éxito en el reequilibramiento del sistema es necesario que se construya una legitimidad de reemplazo en cabeza del nuevo mandatario.

Más allá de estas breves consideraciones sobre la investigación referida —imposible de resumir aquí-, ¿cómo es la situación de los distintos países 
en relación con la institución vicepresidencial? Como se observa en el siguiente cuadro, la mayoría de los países tienen un vicepresidente, un país tiene tres, dos países tienen dos vicepresidentes y dos no tienen esta figura. En todos los casos los vicepresidentes son electos por voto popular lo que hace que tengan legitimidad popular autónoma y el presidente no pueda despedirlos como a un ministro. La excepción es Venezuela, donde el presidente es quien designa al vice y puede destituirlo. La función esencial que tienen los vicepresidentes es reemplazar al presidente en casos de ausencia temporal o definitiva. Asimismo, según los países, las constituciones les otorgan distintas facultades y competencias. Pero más allá de estas facultades normativas o formales, la vicepresidencia permanece en un sitio institucional devaluado, aunque el vice sea el segundo en el organigrama de poder.

Cuadro I. La Vicepresidencia en América Latina

\begin{tabular}{|l|c|c|c|}
\hline \multicolumn{1}{|c|}{ Países } & Un Vicepresidente & Dos/Tres Vicepresidentes & Sin Vicepresidente \\
\hline Argentina & $\mathrm{X}$ & & \\
\hline Bolivia & $\mathrm{X}$ & & \\
\hline Brasil & $\mathrm{X}$ & & \\
\hline Colombia & $\mathrm{X}$ & $\mathrm{X}(2)$ & \\
\hline Costa Rica & & & $\mathrm{X}$ \\
\hline Chile & $\mathrm{X}$ & & \\
\hline Rep. Dominicana & $\mathrm{X}$ & & \\
\hline Ecuador & $\mathrm{X}$ & $\mathrm{X}(3)$ & \\
\hline Guatemala & & & $\mathrm{X}$ \\
\hline Honduras & $\mathrm{X}$ & & \\
\hline México & $\mathrm{X}$ & $\mathrm{X}(2)$ & \\
\hline Nicaragua & $\mathrm{X}$ & & \\
\hline Panamá & & & \\
\hline Paraguay & $\mathrm{X}$ & & \\
\hline Perú & & & \\
\hline Uruguay & & & \\
\hline Venezuela & & & \\
\hline
\end{tabular}

Fuente: Elaboración propia. 
Como se ha señalado, los problemas en relación con la vicepresidencia y los conflictos con los mandatarios han sido una constante en diversos países. Pueden mencionarse al mero ejemplo ilustrativo sólo algunos casos vinculados con la figura, desde la tercera ola de la democratización y que ocurren en los diferentes contextos. En la crisis que envolvió al mandatario colombiano Ernesto Samper respecto del supuesto financiamiento de su campaña por el narcotráfico su vice, Humberto la Calle le pedía su renuncia, en 1996. La posición opositora de la vicepresidente Rosalía Areaga en el proceso de caída del presidente Abdalá Bucarán, en 1997, en el Ecuador. La contradictoria fórmula entre el presidente paraguayo Raúl Cubas Grau y el vicepresidente Luis María Argaña, su asesinato y la crisis institucional emergente La renuncia del vicepresidente Carlos «Chacho» Alvarez ${ }^{7}$, en la Argentina y la crisis institucional posterior de la Alianza gobernante, en 2001. En los últimos años, nuevamente en la Argentina, cabe referir la tormentosa relación entre Cristina Fernández de Kirchner y Julio César Cobos. En el Paraguay el vicepresidente Federico Franco apareció como un opositor del gobierno del presidente Fernando Lugo, quien fue destituido por un juicio político, en 2012. No es este el sitio para desarrollar los conflictos entre presidente y vice, baste entonces señalar que por cierto fueron numerosos.

Además de los diferenes problemas y cuestiones entre presidente y vicepresidente durante la gestión de coexistencia en el gobierno, los vicepresidentes han sido sucesores en numerosos casos, sea por fallecimiento del mandatario o cuestiones de salud y también por crisis políticas que llevaron a las caídas presidenciales, sea por renuncia forzadas por protestas sociales o por procesos de destitución llevados a cabo por el Congreso. Este hecho muestra la importancia del vicepresidente en situaciones de crisis institucionales. En realidad, la vicepresidencia en una institución que opera en momentos de crisis que envuelven a la principal figura del sistema presidencial: el presidente.

Cuadro II. Sucesión de la Vicepresidencia en América Latina en la tercera ola de la democratización

\begin{tabular}{|l|c|l|l|l|}
\hline \multicolumn{1}{|c|}{ País } & $\begin{array}{c}\text { Ańo } \\
\text { de sucesión }\end{array}$ & \multicolumn{1}{c|}{$\begin{array}{c}\text { Presidente } \\
\text { saliente }\end{array}$} & \multicolumn{1}{c|}{$\begin{array}{c}\text { Causa } \\
\text { de la sucesión }\end{array}$} & Vicepresidente \\
\hline Brasil & 1985 & Tancredo Neves & Fallecimiento & Sarney \\
\hline Brasil & 1992 & Collor de Mello & Iimpeachment & Franco \\
\hline
\end{tabular}

7 Ver Serrafero, Mario D. (2007): «Vicepresidencia efímera y ruptura anunciada: el caso de la Alianza», en Anales de la Academia Nacional de Ciencias Morales y Políticas, pp. 5-31. 


\begin{tabular}{|l|c|l|l|l|}
\hline \multicolumn{1}{|c|}{ País } & $\begin{array}{c}\text { Año } \\
\text { de sucesión }\end{array}$ & \multicolumn{1}{c|}{$\begin{array}{c}\text { Presidente } \\
\text { saliente }\end{array}$} & \multicolumn{1}{c|}{$\begin{array}{c}\text { Causa } \\
\text { de la sucesión }\end{array}$} & Vicepresidente \\
\hline Ecuador & 2000 & Jamil Mahud & Golpe & Noboa \\
\hline Bolivia & 2001 & Hugo Banzer & Renuncia & Quiroga Ramírez \\
\hline Bolivia & 2003 & Sánchez de Lozada & Renuncia & Mesa \\
\hline Ecuador & 2005 & Lucio Gutiérrez & Declaración Congreso & Palacio \\
\hline Paraguay & 2012 & Fernando Lugo & Impeachment & Franco \\
\hline
\end{tabular}

Fuente: Elaboración propia.

Por fallecimiento de Tancredo Neves asumió José Sarney en la presidencia de Brasil, en 1985, conduciendo el primer gobierno luego del período militar. También en Brasil, en 1992, el presidente Collor de Mello fue sometido a un proceso de impeachment y finalmente lo sucedió el vice, Itamar Franco. En 2000, Jamil Mahuad fue desplazado por un movimiento de militares y grupos indígenas y luego de unas confusas horas fue sucedido por el vicepresidente Gustavo Noboa. Problemas de salud llevaron a renunciar al presidente Hugo Banzer en Bolivia, en 2001, falleciendo pocos meses después y continúando en el cargo el vicepresidente Jorge Quiroga.

Cabe señalar que no siempre el elegido vicepresidente fue sucesor del mandatario en una situación de crisis. En la Argentina, Carlos Álvarez, vicepresidente de Fernando de la Rúa, había renunciado el año anterior a la caída del presidente producida a fines de 2001. Tras la destitución de Abdalá Bucaram, en 1997, la vicepresidenta Rosalía Arteaga estuvo sólo un breve tiempo en el gobierno pues el sucesor fue finalmente el presidente del Congreso, Fabián Alarcón. En Paraguay, en 1999, el presidente Raúl Cubas Grau fue sometido a un juicio político y terminó renunciando al cargo. La vicepresidencia estaba vacante por asesinato de quien había sido su ocupante y la sucesión recayó en cabeza del Presidente de la Legislatura, Luis Ángel González Macchi.

En síntesis, son muchos los problemas vinculados con la figura de la vicepresidencia en el contexto de gobierno y coexistencia con el presidente. Una somera y no exhaustiva lista incluiría al menos los siguientes: 1) problemas de coexistencia con el presidente; 2) inexistencia del vicepresidente, por no haberse cubierto su vacancia; 3) vicepresidente conflictivo; 4) vicepresidente opositor; 5) vicepresidente conspirador; 6) vicepresidente relegado totalmente por el presidente. La lista podría extenderse.

Por otra parte, en el contexto de sucesión la vicepresidencia se convierte en una figura expectable teniendo en cuenta la inestabilidad de los sistemas políti- 
cos regionales. En numerosos casos han ascendido al poder y piloteado la crisis institucional en una suerte de transición, con distintos resultados.

Luego de este breve panorama sobre cuestiones teóricas y empíricas de la vicepresidencia latinoamericana a continuación se desarrolla la evolución que ha tenido la institución en los Estados Unidos.

\section{LA VICEPRESIDENCIA EN LOS ESTADOS UNIDOS}

Hamilton en El Federalista señalaba en relación a los dos objetivos que justificaban la institución ${ }^{8}$ : «El hecho de que se nombre a una persona especial para el puesto de vicepresidente ha sido objetado como superfluo, sino ya perjudicial. Se sostiene que hubiera sido preferible autorizar al Senado para que eligiera dentro de sí mismo un funcionario que ocupara ese cargo. Pero hay dos consideraciones que parecen justificar las ideas de la convención acerca del asunto. Una es que para asegurar en todo tiempo la posibilidad de una resolución definida en ese cuerpo, es necesario que el presidente tenga únicamente voto de calidad. Y sacar al senador de un Estado de su curul para ponerlo en la del presidente del Senado, sería cambiar respecto del Estado un voto constante por un voto eventual. La consideración restante consiste en que como el vicepresidente puede sustituir ocasionalmente al presidente en la suprema magistratura ejecutiva, todas las razones que apoyan el modo de elegir prescripto para el uno se aplican con gran fuerza a la manera de designar al otro» ${ }^{9}$. En otras palabras, se le encontraba un lugar en el Senado resolviéndose el tema de su presidencia y la igual representación de las provincias en el cuerpo. Y como el vicepresidente podría sustituir al presidente, las normas de elección de éste debían aplicarse a aquél.

En los EE.UU. la imagen devaluada de la vicepresidencia imperó durante más de dos centurias. John Adams decía: «My country in its wisdom has contrived for me the most insignificant office that ever the invention of man contrived or his imagination conceived...».Y, en tiempos más recientes, el escritor norteamericano Arthur Schlesinger sugirió la abolición de la vicepresidencia,

8 La creación del cargo es ubicable en la Convención de Filadelfía, donde se discutió también su utilidad y eficacia encontrándose detractores y sostenedores, pero aún estos últimos no demostraron un mayor convencimiento. Ver el trabajo de Roberto García Martínez, «La Vicepresidencia de la República», La Ley (197), tomo 145, pp. 802-808.

9 Hamilton en Hamilton, Madison y Jay (1974), El Federalista, México, Fondo de Cultura Económica, n. ${ }^{\circ}$ LXVIII, pp. 290 y 291. 
expresó sobre su titular: «the vice-president has only one serious job: to wait around for the president die» ${ }^{10}$.

En los EE.UU. se ha remarcado también su naturaleza híbrida, esa suerte de purgatorio donde se aloja este funcionario que no parece integrar claramente ni el Poder Ejecutivo ni el Legislativo. Así el politólogo Clinton Rossiter afirmó en relación al lugar del vicepresidente: «suspended in a constitutional limbo between executive and legislature, and in a political limbo between obscurity and glory?» ${ }^{11}$, W. Wilson señalaba ya, en el siglo pasado, este impreciso lugar de la vicepresidencia ${ }^{12}$.

La inquietud que provoca a veces la presencia del vicepresidente también se ha remarcado, en expresiones de Albert Schweitzwer: «In fact, presidents don't even like to see a vice-president around. They are constant remainders of their own mortality» ${ }^{13}$. Como en el caso argentino, también el presidente norteamericano no se ha sentido siempre cómodo frente a una figura a la espera del reemplazo.

En cuanto a la selección del vicepresidente, Cronin señala que a menudo son realizadas apuradamente atendiéndose más al balance de la fórmula que a la propia persona que podría llegar a ejercer la presidencia ${ }^{14}$, como también ha sucedido en América Latina. McConnell advierte que si bien en la selección del vice el presidente ocupa un papel sustancial, se atiende especialmente al aporte que podría significar el candidato a la vicepresidencia al triunfo de la fórmula ${ }^{15}$. Casi todos los autores destacan que en la designación del candidato a la vicepresidencia, el apoyo electoral que agregue es un factor esencial.

Asimismo, señala Cronin que un presidente no dejará que su vice le haga sombra y podrá asignarle, entonces, tareas partidarias y rutinarias, demostrando además que el mandatario está por sobre la política cotidiana ${ }^{16}$.

Ratificando la sospecha sobre la poca disposición de los vicepresidentes de ser meros continuadores de las políticas de los presidentes que reemplazan, Burns advierte que los vices que accedieron a la presidencia intentaron también impo-

$10 \quad$ LawScope, Vol. 63 (1977), pág. 21.

11 Time, 15 de octubre de 1973, pág. 25.

12 Opiniones de vicepresidentes norteamericanos que resaltan el papel relegado de la institución, pueden verse en Pierre, Henri (1992), La Casa Blanca. En los años de Reagan y Bush, Bs. As., Vergara, 1992, capítulo «La vicepresidencia».

13 Law Scope, January 1977, Vol. 63, pág. 21.

14 Cronin, Thomas (1980): The State of the Presidency, United States of America; Little, Brown and Company, pág. 41.

15 McConnell, Grant (1976): The Modern Presidency, New York, St. Martin’s Press, pág. 33.

16 Cronin, Thomas (1980): The State of the Presidency, citado anteriormente, pág. 112. 
ner su sello personal, más allá de haber sido electos en la misma fórmula del presidente al que reemplazaron. Tales fueron los casos de Coolidge, T. Roosevelt, Truman, Johnson ${ }^{17}$.

Los autores norteamericanos suelen distinguir entre los poderes otorgados por la Constitución y las funciones y papeles desempeñados a lo largo del tiempo como una suerte de práctica institucional o para-constitucional. En cuanto a sus funciones constitucionales, el vicepresidente ejerce un papel menor como presidente nato del Senado, dirige y controla los debates pero no interviene en ellos y sólo puede votar en caso de empate ${ }^{18}$. Y a partir de 1947 es miembro del «National Security Council».

Es en el campo de las prácticas donde se ha notado el papel incrementado. Es así que la vicepresidencia en los EE. UU. ha sufrido una gran transformación en las últimas décadas, habiéndose producido una expansión de sus funciones principalmente bajo el período de Rockefeller y Mondale. Este último vicepresidente había aceptado el cargo con el convencimiento que no iba a desarrollar sólo un papel ceremonial ${ }^{19}$.

Paul Light —un especialista de los estudios sobre la vicepresidencia - señala que el staff de la vicepresidencia creció de 20 —en 1960_a 70 miembros en la administración de Carter. Este dotó a la vicepresidencia de una carácter o papel de consejero político, contribuyendo con sus análisis al proceso de toma de decisiones de la presidencia. Burke observa que el presupuesto de la oficina creció significativamente a partir de la administración Kennedy, su organización es una suerte de réplica menor de la presidencia con el jefe del «staff», secretario de prensa, los colaboradores del Consejo Nacional de Seguridad, consejo legal, asistentes para las relaciones con el legislativo, etcétera ${ }^{20}$. El staff de la vicepresidencia se divide en dos grupos. La oficina legislativa que se encarga de las reuniones con los miembros del Congreso y asesora al vicepresidente, y está ubicada en el edificio del Senado. Y la oficia ejecutiva ${ }^{21}$ —ubicada en el «Executive Office Building» próxima a la Casa Blanca- que apoya la tarea del vice en cuestiones de política nacional e internacional, maneja la agenda de reuniones,

17 Ver también MacGregor Burns, James (1973): Presidential Government, Houghton Mifflin Company Boston, pág. 197.

18 Pueden señalarse los siguientes casos de votos de desempate: John Adams, 29 veces; John Calhoun, 28 veces; y más recientemente, Johnson, 1; Agnew, 2; Mondale, 1; y Bush, 5.

19 Time, 26 de julio de 1976, pág. 36.

20 Ver Burke, John P. (1992): The Institutional Presidency, The Johns Hopkins University Press, pág. 23.

21 Ver Edwards III, George C. y Wayne, Stephen J. (1985): Presidential Leadership, St. Martin’s Press, New York, pág. 193. 
relación con los medios, viajes, etcétera. Burns señala que en el siglo pasado existió una suerte de tradición de dejar a los vicepresidentes fuera de la órbita presidencial, ya fuese por su menor experiencia en temas administrativos - $y$ más en legislativos - o porque representaban fracciones partidarias opuestas a la del presidente. Para Burns, en las últimas décadas y trás las experiencias de Roosevelt-Wallace, Eisenhower-Nixon, Kennedy-Johnson, y Johnson-Humprey, la vicepresidencia parece haber entrado en la órbita de la estructura y la toma de decisiones de la presidencia ${ }^{22}$.

El incremento de las facultades y roles no depende de la ley, por tanto, si los próximos presidentes no quisieran vicepresidentes activos no estarían obligados a mantenerlos. Pero los presidentes — hasta ahora- adbieren a los precedentes y tales prácticas están formando parte de la oficina de la presidencia ${ }^{23}$.

Por cierto que en favor del incremento de las funciones y de la importancia de la oficina también obraron ciertos hechos que pusieron de manifiesto el papel crucial del vicepresidente en la órbita del Ejecutivo. Así, cabe mencionar la muerte repentina de F. Roosevelt, la enfermedad de Eisenhower y el asesinato de Kennedy.

\section{PRECEDENTES Y PRÁCTICAS PARACONSTITUCIONALES}

Los precendentes y las prácticas institucionales fueron los factores que aumentaron el papel de la vicepresidencia en el siglo XX y que continúa hasta nuestros días. Pero algunos roles de los modernos vicepresidentes fueron ya trazados a principios del siglo XIX y del XX. Así, por ejemplo el activismo de Jefferson en el liderazgo en el Congreso, y el uso de la prensa por parte de $\mathrm{T}$. Roosevelt para formar la agenda nacional.

Light señala algunas funciones o nuevas actividades y sus precendentes. Así la participación en reuniones de gabinete fue considerada en los últimos años del siglo XIX. Adams fue el último en participar hasta que Wilson le pidió a Thomas Marshall que presidiera las sesiones en ocasión de su viaje al exterior por el 134-136.

22 Ver MacGregor Burns, James (1973): Presidential Government, citado anteriormente, pág.

23 Hay «lecciones acumuladas» que deberían aprender los nuevos vicepresidentes (para tal objetivo existieron, por ejemplo, encuentros entre Rockefeller y Mondale para transmitir las operaciones y tareas del staff vicepresidencial). Ver Pika, Joseph «A new Vice Presidency?» (1988): en Nelson, Michael: The Presidency and the Political System, Washington, Vanderbilt University, pág. 466. 
tratado de Versailles. Bajo Herbert Hoover, la práctica de inclusión de los vices fue rutinariamente seguida.

En relación a la representación en el exterior, John Garner (1933-1940), fue el primero en viajar fuera del país en representación oficial. Henry Wallace fue enviado varias veces en misiones internacionales en la época de la Segunda Guerra. El vicepresidente de Truman, Alben W. Barkley, desplegó actividades ceremoniales que serían regularmente ejercitadas con posterioridad. Es así que, desde hace décadas, el vicepresidente representa al presidente en el mundo, en cambios de gobierno o funerales. Rockefeller concurrió al funeral de Chiang Kai-shek y al del rey Faisal de Arabia Saudita. Mondale al de Tito. Bush viajó a Rusia cuando murió Brezhnev, en 1982 y podrían multiplicarse los ejemplos.

En cuanto a su inclusión en el Senado, sorprende que siendo su presidente haya demorado tanto su actividad de lobbysta. Pero también, desde allí, algunos vicepresidentes «conspiraron» contra la política del presidente. Garner fue un efectivo lobbista del New Deal hasta que afirmó su independencia en relación a la propuesta de expansión de la Corte. Y sobrevino la ruptura con Roosevelt cuando el presidente quebrantó la tradición de la reelección inmediata por una única vez. Roosevelt se arrogó el derecho de elegir al acompañante de fórmula. Antes no había mayor interés de que ambos constituyeran un «team». A partir de 1940 los presidentes ganaron el derecho de escoger a sus vices y con esto fue más probable que asumieran el papel de «advisers» (consejeros) ${ }^{24}$.

En la tarea de Lobby la experiencia legislativa es un factor importante y pueden citarse — entre otros — los casos de Nixon, Johnson, Humprey, Ford y Mondale. Rockefeller fue un gran lobbysta más allá de no haber tenido antecedentes en la materia.

El papel del vicepresidente se ha ampliado en las últimas décadas ya sea a través de funciones más rutinarias o tareas más específicas. Johnson coordinó los esfuerzos de la administración para eliminar la discriminación racial y promovió la exploración del espacio exterior, ejercitó su influencia en el Congreso y junto a Kennedy realizaba los «desayunos de trabajo» con los líderes del Legislativo. Rockefeller tuvo un importante papel en el diseño de las políticas presidenciales, sostuvo reuniones a lo largo del país para identificar y discutir lo problemas y brindar propuestas. Mondale tuvo un poderoso papel de consejero de Carter. El presidente le dio espacio y maniobra para intervenir en el análisis y las decisiones de gobierno. Influyó dentro del Congreso y tejió alianzas con distintos grupos fortaleciendo las bases del gobierno. Tuvo un importante poder en la sombra y

24 Ver también MacGregor Burns, James (1973): Presidential Government, citado anteriormente, pág. 170 . 
premeditadamente se abstuvo de la atención pública ${ }^{25}$. Según Light, el éxito de Mondale tuvo que ver con ciertas reglas tales como: un bajo perfil frente a la prensa, no sacarle crédito a la labor presidencial, apoyar las políticas del presidente y compartir con él los trabajos menos gratos.

A pesar de lo cambios referidos, la imagen de la vicepresidencia no se ha liberado de sus estereotipos. Así para George Bush — devoto vicepresidente de Ronald Reagan - es una de las instituciones menos comprendidas del sistema norteamericano. Para Bush, los atributos esenciales del cargo son la subordinación, la lealtad y la confidencialidad; un vice desafiante del lugar presidencial sería un serio problema para las instituciones de los EE.UU. ${ }^{26}$. Su vicepresidente, Dan Quayle, tuvo un papel importante en la administración y, la relaciones con el presidente fueron muy buenas y aceitadas por el encuentro frecuente ${ }^{27}$. No obstante, Quayle fue motivo y centro del humor político y nunca fue visto como posible presidente ${ }^{28}$. El siguiente vicepresidente, Al Gore, tuvo también una muy buena relación con su presidente Bill Clinton, fue reelecto con él y aparecía como posible sucesor para las elecciones presidenciales próximas. La cercanía entre Clinton y Gore se extendió, incluso, a los aspectos más sombríos de la administración, como las sospechas de corrupción que envolvieron a la presidencia $^{29}$. No obstante esta proximidad, al lanzar su campaña presidencial para el año 2000, Gore tomó distancia de Clinton y criticó su comportamiento por el caso Mónica Lewinsky. Señaló que el presidente le había mentido y que el affaire que puso en situación de crisis al gobierno, constituía un hecho «inexcusable...terrible....horrible» ${ }^{30}$. Marcando diferencias con su compañero de fórmula, sostuvo que se comprometía a devolver al país los «valores familiares». Clinton, por su parte, se sintió sumamente molesto por la actitud de distancia-

25 Sobre estas vicepresidencias ver Edwards III, George C. y Wayne, Stephen J. (1985): Presidential Leadership, citado anteriormente, pp. 190-193.

26 Woodward, Bob y Broder, David S. (1992): The Man Who Would Be President. Dan Quayle, New York, Simon \& Schuster, pp. 92 y 93.

27 Presidente y vicepresidente se reunían todos los jueves a almorzar y se hablaban diariamente por teléfono.

28 Sobre algunos aspectos de Dan Quayle ver el texto citado de Woodward y Broder (1992).

29 Ver Coulter, Ann (1988): High Crimes and Misdemeanors. The case against Bill Clinton, Washington, Regnery, pp. 217-218, y 275.

30 Ver La Nación, 17 de junio de 1999, pág. 5. Estas expresiones las realizó en el lanzamiento formal de su candidatura en Carthage, Tennesse, Estado natal de Gore. El vicepresidente si bien criticó el comportamiento de Clinton por el caso Lewinsky, también resaltó los éxitos de la gestión demócrata. 
miento y crítica de su vicepresidente, considerándola «un acto de ingratitud que raya en la deslealtad» ${ }^{31}$.

Desde otra perspectiva interesante, Denenberg señala que el vicepresidente tiene rivales que le pueden quitar o disminuir su potencial poder. Uno de ellos sería el «First Friend» como fue el caso de James Baker, Secretario de Estado del presidente Bush. Otro sería el jefe del staff de la Casa Blanca, figura que puede servir hasta de fusible en casos de crisis políticas. También la Primera Dama —»First Lady»— puede adquirir un especial protagonismo como ocurrió en parte de la administración Clinton ${ }^{32}$.

Joel K. Goldstein ${ }^{33}$, estudioso de la vicepresidencia norteamericana, observó el giro extraordinario que se dio a partir de la experiencia de Walter Mondale. Gracias al impulso dado por Jimmy Carter, el vice fue un asesor del presidente, un «solucionador de problemas» y no necesariamente con responsabilidades de línea. Los vicepresidentes posteriores mantuvieron estos papeles de la vicepresidencia con variaciones, de acuerdo a sus propios estilos. Bush y Quayle tuvieron un papel menos importante como asesores del mandatario. Gore, en cambio, fue un vicepresidente que jugó enorme rol como consejero del presidente Clinton y sólo se distanció de éste — como se señaló — en ocasión del caso «Lewinsky» y en vistas a su campaña por la presidencia. Sin duda, la vicepresidencia de Dick Cheney fue la más robusta en la historia norteamericana a punto tal que Blumenthal acuñó el término «Imperial Vice President», recordando el título de la obra de Arthur Schlesinger (Jr.) que obtuvo el Premio Pulitzer: «The Imperial Presidency».

En definitiva, el vicepresidente ha ganado tarea o funciones más allá del silencio constitucional y su limbo institucional, y de la persistencia de las imágenes que poco la favorecen. Hoy día incluso cabe esperar de un vicepresidente su participación en el gabinete, su «lobbying» en el Senado, la representación del presidente en el exterior, el papel de consejero presidencial y el desarrollo de tareas importantes que pueda encomendarle el presidente. Y el vicepresidente puede esperar, a su vez, proyección hacia el futuro, incluso la sucesión presidencial. Así se ha señalado que constituye un campo de experiencia y preparación para el cargo máximo: hacia finales del siglo XX trece de los cuarenta presidentes norteamericanos sirvieron en la vicepresidencia ${ }^{34}$.

\footnotetext{
31 Ver La Nación, 27 de junio de 1999, pág. 4.

32 Ver Denenberg, R. V. (1996): Understanding American Politics, Glasgow, Fontana Press, pp. $85-87$.

33 Goldstein, Joel (2008): «The Rising Power of the Modern Vice Presidency», en Presidential Studies Quarterly, citado anteriormente.

34 Elowitz, Larry (1992): Introduction to Government, New York, Harper Collins Publishers, pág. 115 .
} 


\section{INHABILIDAD Y VACANCIA PRESIDENCIAL}

Wilson advierte dos cuestiones vinculadas con la problemática de la sucesión. En primer lugar, ¿qué ocurre si el presidente se encuentra gravemente enfermo?. En segundo lugar, si el vicepresidente debe asumir la presidencia. un político no elegido por el pueblo podría ocupar su lugar ${ }^{35}$. Cuando la vicepresidencia se encuentra vacante es necesario contar con una sucesión prevista. Han existido diferentes leyes, a través del tiempo, que fueron estableciendo distintas soluciones $^{36}$.

Ambos problemas — el de la inhabilidad y el de la vacancia- se resolvieron en 1967 con la enmienda XXV, cuyo texto es el siguiente: «Sección 1. En caso de destitución del presidente, o de su muerte o renuncia, el vicepresidente se convertirá en presidente. Sección 2. Cuando quede vacante la vicepresidencia, el presidente nombrará a un vicepresidente que asumirá sus funciones una vez confirmado por el voto de la mayoría de ambas Cámaras del Congreso. Sección 3. Cuando el presidente comunique formalmente por escrito al presidente provisional del Senado y al presidente de la Cámara de Representantes, que se halla incapacitado para ejercer los poderes y obligaciones propios de sus funciones, y hasta tanto él les comunique formalmente por escrito lo contrario, tales poderes y obligaciones serán desempeñados por el vicepresidente como presidente interino. Sección 4. Cuando el vicepresidente y una mayoría de los principales funcionarios del poder ejecutivo, o bien de cualquier otro cuerpo que por ley dispusiere el Congreso, comunique formalmente por escrito al presidente provisional del Senado y al presidente de la Cámara de Representantes que el presidente está incapacitado para ejercer los poderes y obligaciones propios de sus funciones, el vicepresidente asumirá inmediatamente los poderes y obligaciones de la presidencia en carácter de presidente interino. Posteriormente, cuando el presidente comunique formalmente por escrito al presidente provisional del Senado y al presidente de la Cámara de Representantes que ha cesado su incapacidad, reasumirá los poderes y funciones de presidente, a no ser que, antes de transcurridos cuatro días, el vicepresidente y una mayoría de los principales funcionarios del poder ejecutivo o bien cualquier otro cuerpo que por ley dispusiere el Congreso, comuniquen formalmente por escrito al presidente

35 Wilson recuerda los problemas de salud de James A. Garfield, Woodrow Wilson, Eisenhower y Reagan. En cuanto a la vacancia, en ocho ocasiones — como se vio en otro capítulo- los vicepresidentes asumieron por muerte del presidente en ejercicio. Ver Wilson, James Q. (1992): American Government, Lexington, D.C. Heath and Company, pp. 357-358.

36 Puede verse el artículo de Montoya, Mario Daniel, «El vicepresidente de los Estados Unidos. Su acceso a la presidencia y reemplazo en caso de vacancia», en La Ley, 4 de julio de 1991. 
provisional del Senado y al presidente de la Cámara de Representantes que el presidente se halla incapacitado para ejercer los poderes y obligaciones de la presidencia. El Congreso procederá entonces a dirimir la cuestión reuniéndose en asamblea con ese propósito dentro de las cuarenta y ocho horas, si no estuviese sesionando. Si dentro de veintiún días de haber recibido la última declaración escrita, o si el Congreso no estuviera sesionando. dentro de veintiún días de haber sido convocado, el Congreso determina por dos tercios de los votos de ambas Cámaras que el presidente está incapacitado para ejercer los poderes y obligaciones de la presidencia, continuará desempeñándolos el vicepresidente como presidente interino; de lo contrario, el presidente reasumirá los poderes y obligaciones presidenciales».

La enmienda fue propuesta por el Senador Birch Bayh y el representante Emanuel Celler. La sección 2 establece el modo de designación del sucesor a través de un mecanismo donde el presidente y las Cámaras toman parte. La sección 4 le da al vicepresidente un papel estelar para decidir acerca de la incapacidad del presidente.

Una de las críticas realizadas a la sección segunda de la enmienda es que se dejaba abierta la puerta para que la presidencia y la vicepresidencia fuera ocupada por funcionarios que no habían sido elegidos por el voto del pueblo, violándose además el artículo II, sección I de la Constitución de los EE.UU. Además, la inexistencia de campaña electoral privaba al sucesor de una importante experiencia en debates de ideas y conocimiento de los problemas y necesidades de la Nación ${ }^{37}$.

La sección 2 de la enmienda se utilizó ante la renuncia del vicepresidente Spiro Agnew, el 10 de octubre de 1973. El presidente Nixon designó entonces a Gerald Ford. A su vez y ante la renuncia de Nixon, en agosto de 1974, Ford se convirtió en presidente y propuso para cubrir la vacante de la vicepresidencia a Nelson Rockefeller. Fue ésta la primera vez en la historia de los EE.UU. en que ni presidente ni vicepresidente habían sido designados por elección popular. Más allá de las críticas que recibió la enmienda en el caso concreto, Pius —entre otros autores - señala que mantiene la legitimidad constitucional, los principios del gobierno limitado y poliárquico y los funcionarios son responsables por su actuación. Y en relación a las vacantes cubiertas por Ford y Rockefeller estima que la enmienda veinticinco funcionó relativamente bien $^{38}$. Los problemas cardíacos

\footnotetext{
37 Mondale, Walter (1975): The Accountability of Power, New York, pág. 74.

38 Ver Pius, Richard M. (1979): The American Presidency, New York, Basic Books Inc., pág. 117-119; Toinet, Marie-France (1994): El sistema político de los Estados Unidos, México, Fondo de Cultura Económica, 1994, pp. 129 y 130.
} 
del vicepresidente, Dick Cheney, reactivaron la discusión acerca de la vacancia de la vicepresidencia en los EE.UU. ${ }^{39}$

\section{LA EXPERIENCIA DEL CASO NORTEAMERICANO}

La rápida mirada realizada sobre la institución en los EE.UU. permiten las siguientes consideraciones:

En primer lugar, muchos problemas advertidos en relación con la vicepresidencia latinoamericana, aparecieron también históricamente en suelo norteamericano, por ejemplo la desvalorización de la institución, la designación del candidato por distintos intereses, etcétera.

En segundo lugar, en los EE.UU. ha existido una evolución de la institución basada menos en lo normativo que en las prácticas institucionales y los antecedentes acumulados. Tal evolución ha significado un papel más relevante del vicepresidente asignándole tareas generales y específicas. El nuevo activismo de la vicepresidencia se ha dado dentro de la órbita del poder y de la estructura presidencial.

En tercer lugar, la normativa constitucional — la enmienda XXV- solucionó aspectos ambiguos y/o conflictivos en relación con la inhabilidad presidencial y la vacancia de la vicepresidencia. En relación a la inhabilidad presidencial aparece un papel importante del vicepresidente. En relación a la vacancia del vicepresidente, es el presidente quien tiene un papel crucial (vinculado al Congreso), acentuando un tipo de fórmula solidaria (de gobierno).

Por último, a diferencia de América Latina, en los EE.UU. ha existido un mayor interés en torno de la posible reforma de la institución. Así se han brindado distintas propuestas — que no necesariamente requerirían una modificación constitucional - como la delegación al vice de ciertas obligaciones del presidente, la democratización del proceso de selección que garantice un candidato con estatura política propia, la elección separada del presidente y del vicepresidente (aunque recaiga en miembros de distintos partidos), etcétera; y no ha faltado la propuesta de eliminar la figura ${ }^{40}$.

39 Ver Marianne Means, «The US vice-presidency examined», en Buenos Aires Herald, 11 de marzo de 2001, pág. 7.

40 Ver Denenberg, R. V. (1996): Understanding American Politics, citado anteriormente, pp. 87-90. 


\section{CONCLUSIONES: ¿UNA NUEVA VICEPRESIDENCIA?}

Los problemas con la institución vicepresidencial han aparecido reiteradamente en la tercera ola de la democratización e incluso antes ya existían numerosos ejemplos en la política comparada latinoamericana. Como he señalado en otras oportunidades, frente a una performance de la vicepresidencia con numerosos problemas en el sistema político e institucional caben las siguientes alternativas, según la evaluación a realizar en cada país: a) eliminar la vicepresidencia; b) aprovechar una reforma constitucional para modificar características de la figura y c) comenzar un camino de prácticas paraconstitucionales para que la vicepresidencia cumpla otro papel en el régimen presidencial.

En los países donde la dinámica entre presidente y vice ha mostrado conflictos y tensiones eliminar la figura puede ser una alternativa. Existen países donde no hay vicepresidente y los sistemas políticos suplen de otro modo los casos de accidentes institucionales donde está comprometida la figura presidencial y la gobernabilidad del sistema.

Asimismo, tanto en la alternativa de una posible reforma constitucional que contemple también a la vicepresidencia como en la opción de una modificación de las prácticas paraconstitucionales, el caso norteamericano puede considerarse para el debate. No es la única propuesta que podría pensarse, pero al menos es una disponible que presenta una cuota importante de interés y de concreción en un país presidencialista.

Desde esta perspectiva, una nueva vicepresidencia debería sostenerse en nuevas prácticas institucionales — con reforma o no de la Constitución- que crearan entre presidente y vice relaciones de cooperación y no de conflicto. El nuevo activismo de la vice presidencia debería darse dentro de la órbita del poder Ejecutivo y de la estructura presidencial, convirtiéndose en un asesor privilegiado del primer mandatario. Asimismo, significaría una evolución que el presidente le asignara a su vicepresidente tareas generales y específicas de relevancia. En este marco de tareas y vinculaciones es esperable que se desarrollen más vínculos cooperativos que confrontativos. Estas consideraciones no significan que el vicepresidente deba ser un apéndice clonado del mandatario desplegando una solidaridad absoluta y acrítica del presidente, pues tiene también sus propias opiniones y convicciones, además para que su asesoramiento sea eficaz debe tener sus propias perspectivas. Pero cuando existan diferencias, como las que evidentemente ocurrieron en el caso norteamericano incluso en binomios que funcionaron armónicamente, la vitrina pública de los medios es el peor escenario para plantearlas y menos aún resolverlas. Por último cabe señalar una diferencia en relación a determinadas normativas en América Latina y que opera como poderoso 
incentivo para la cooperación en el caso norteamericano y es la posibilidad de sucesión del vicepresidente cuando el presidente encuentra agotada su posibilidad de reelección.

Puede haber por cierto otras formas de repensar la vicepresidencia, pero ésta es una de ellas: la que ofrece la experiencia norteamericana. Lo más importante que cabe destacar es que el campo de investigación sobre la vicepresidencia latinoamericana es un campo casi inexplorado y es hora de comenzar a transitarlo. A partir de los resultados de investigación que se generen en cada país existirán más alternativas para reprensar y, en su caso, reformar la vicepresidencia pues se trata del segundo puesto institucional en el régimen presidencial y merece una mayor atención de la que se le ha prestado hasta el presente.

Title:

TOWARDS A NEW VICE PRESIDENCY? REFLECTIONS ON THE NORT AMERICAN CASE

\section{Summary:}

I. Introduction. II. The problems of Vice Presidency: theory and facts. III. The Vice Presidency in the United States. IV. Paraconstitutional precedents and practices. V. Disability and presidential vacancy. VI. The experience of the U.S. case. VII. Conclusions. A new Vice Presidency?

\section{Palabras Clave:}

Vicepresidencia - Vicepresidencia en Estados Unidos - Vicepresidencia en América Latina - Presidencialismo.

Key words:

Vice Presidency - Vice Presidency in United States -Vice Presidency in Latin America -Presidentialism.

\section{Resumen:}

En los regímenes presidenciales de América Latina la vicepresidencia ha sido poco estudiada, a diferencia de los Estados Unidos. Apenas recibió algunos comentarios de autores, como Juan Linz, dudando de su eficacia y señalando algunos de los problemas que rodean su figura, como los criterios de nominación de los candidatos y los conflictos con los presidentes. Pero, prácticamente, la vicepresidencia no se tuvo en cuenta en el debate crítico en relación con el presidencialismo y el parlamentarismo, a pesar de ser el segundo puesto en 
importancia en el régimen presidencial. Vuelta la democracia en la región, la vicepresidencia ha generado numerosos problemas políticos, sin embargo no existe prácticamente un debate académico sobre ella. Tensiones y graves conflictos entre el presidente y el vicepresidente, hasta vicepresidentes convertidos en opositores son algunos de los problemas observados. Por otra parte, algunos vicepresidentes han ocupado, con distinta suerte, el lugar del presidente ya sea tanto por su fallecimiento como por crisis políticas que culminaron con la salida del mandatario.. En los Estados Unidos, históricamente, existía la imagen devaluada de la vicepresidencia y problemas similares a los observados en América Latina. Pero en el país del norte la vicepresidencia ha sido estudiada desde hace tiempo y la institución ha evolucionado a través de prácticas paraconstitucionales. Ahora la vicepresidencia es una pieza importante del sistema institucional y se encuentra ubicada en la órbita del Ejecutivo. Ha ganado tareas, nuevas funciones e influencia, más allá de la persistencia de las imágenes que poco la favorecen. Debido a esta evolución paraconstitucional cabe esperar de un vicepresidente su participación en el gabinete, su «lobbying» en el Senado, la representación del presidente en el exterior, el papel de consejero presidencial y el desarrollo de tareas importantes que pueda encomendarle el presidente. Y el vicepresidente puede esperar, a su vez, proyección hacia el futuro, incluso la sucesión presidencial. Así se ha señalado que constituye un campo de experiencia y preparación para el cargo máximo: hacia finales del siglo XX trece de los cuarenta presidentes norteamericanos sirvieron en la vicepresidencia. En síntesis, en este estudio se brinda un enfoque de análisis de la vicepresidencia y se tratan algunos de los problemas que ha presentado en los países de America Latina. Luego se realiza un análisis de la experiencia norteamericana y de la evolución de la institución en ese país. El análisis del caso norteamericano resulta útil para iniciar un debate sobre la vicepresidencia en la región, para explorar una necesaria agenda de investigación y como una de las alternativas posibles a la hora de su reforma.

\begin{abstract}
:
In the Presidential Regimes of Latin America, the institution of the Vice Presidency has been barely studied, unlike that of the United States. It only received some comments from authors such as Juan Linz, doubting its effectiveness and pointing out some of the issues surrounding its figure, like the criteria for nomination of candidates and conflicts with the Presidents. But Vice Presidency was practically not taken into account in the debate on presidencialism and par-
\end{abstract}


lamentarism, despite being the second place of importance in a presidential regime. With democracy back in the region, Vice Presidency has generated numerous political problems, but there virtually isn't any academic debate on this. Severe tensions and conflicts between the President and Vice President, even Vice Presidents turned into opponent, are some of the problems observed. On the other hand, some Vice Presidents have taken, with varying success, the role of President be it because of the former's death or because of political crisis that culminated with the resignation of the President. In the United States, historically, there has been a devalued image of Vice Presidency and similar problems observed in Latin America. But in the United States, Vice Presidency has been studied for some time and the institution has evolved through para-constitutional practices. Now, Vice Presidency is an important part of the institutional system and it is located in the orbit of the Executive Branch. It has earned tasks, new roles and influence, beyond the persistence of the images that do little in its favor. Due to this para-constitutional evolution, it is to be expected, from a Vice President, his participation in the Presidential Cabinet, his «lobbying» in the Senate, the representation of the President in foreign countries, the role of presidential adviser and the development of important tasks that the president might command to him. And the Vice President can expect, as well, a good position in the future, even presidential succession. This is how it has been pointed out that it constitutes a field of experience and preparation for the maximum institutional position: towards the last of the 20th Century, thirteen out of the forty North American Presidents served in Vice Presidency. To summarize, this study provides a focused analysis on Vice Presidency, and deals with some of the problems that it has brought upon Latin American countries. Then, an analysis of the North American experience and the evolution of the institution in this country, is formulated. The analysis of the North American case results useful to initiate a debate on Vice Presidency in the region, to explore a necessary research agenda and as one of the possible alternatives at the time of its reform. 
